\title{
Agar as a Carbon Source and its Effect on the Utilization of Other Carbon Sources by Acetate Non-utilizing ( $a c u)$ Mutants of Aspergillus nidulans
}

\author{
By M. PAYTON, W. MCCULLOUGH AND C. F. ROBERTS \\ Department of Genetics, University of Leicester, Leicester LEI $7 R H$
}

(Received 9 October 1975; revised 29 December 1975)

\begin{abstract}
INTRODUCTION
The presence of two major types of polysaccharide in agar - neutral agarose and charged agaropectin - was first recognized by Araki (reviewed 1959). More recently agar has been shown to consist of a family of linear polymers of variously modified galactose residues (Duckworth \& Yaphe, 1971). The best characterized of these polymers is agarose, the principal gel-forming agent in agar, in which 3 -linked $\beta$-D-galactopyranose residues and 4-linked 3,6-anhydro- $\alpha$-L-galactopyranose residues are arranged alternately (Rees, 1969). This polymer probably forms a network gel through crosslinking of helical chains between regions of double-helix (Rees, 1972). The agaropectins are a group of less well defined molecules of the same polymer structure as agarose but with regions in which the galactopyranose units are substituted with sulphate, pyruvic acid acetals or methoxy residues (Rees, 1969; Young, Duckworth \& Yaphe, 1971).

The presence in agar of small amounts of compounds promoting microbial growth has been recognized, and these contaminating nutrients, often vitamins, can be readily removed by washing the agar in water (Ryan, 1950). Agar may also contain antagonists to microbial growth. Inhibition of bacterial growth by long-chain fatty acids, which could be removed by washing in alcohol, has been noted (Sykes, 1956). Virus growth may be affected, and in some cases the inhibiting agent, which can be removed by washing the agar in water, appears to be an agaropectin component (Takemoto \& Liebharber, 196I). Agar can also antagonize the activity of some microbial growth inhibitors. Thus the concentrations of phenols (Sands \& Bennett, 1964) and of certain antibiotics (Iyer \& Iyer, 1960; Hanus, Sands \& Bennett, 1967) required to inhibit bacterial growth are greater on agar plates than in liquid media.

While it is widely recognized that agar can provide a carbon source for microbial growth, it is generally believed that the carbon source is hexoses utilized through glycolysis. However, we present evidence suggesting that the fungus Aspergillus nidulans utilizes agar as a carbon source through $\mathrm{C}_{2}$ metabolism rather than glycolysis. We have also observed antagonistic effects of agars on the utilization of lactic and succinic acids and of certain amino acids as carbon sources for growth by mutants with lesions in intermediary metabolism. These compounds support the growth of some acetate non-utilizing (acu) mutants of $A$. nidulans in liquid media, whereas there is no growth on the same media solidified with agar. Our data illustrate how the presence of agar in test media can generate both false positive and false negative results.
\end{abstract}




\section{METHODS}

Strains. The strains of Aspergillus nidulans used derived from the Glasgow stock and all were in the R2I genetic background, pabaAI yAz (requirement for $p$-aminobenzoic acid, yellow conidia). The origins of the various mutations and their associated enzyme lesions are given in Table $\mathbf{I}$.

Media. The defined minimal medium contained ( $\mathrm{g} / \mathrm{l}$ distilled water): $\mathrm{KNO}_{3}, 6 \cdot 0 ; \mathrm{KCl}$, $0.52 ; \mathrm{KH}_{2} \mathrm{PO}_{4}, \mathrm{I} \cdot 52$; and a trace elements solution (Armitt, McCullough \& Roberts, 1976 ).

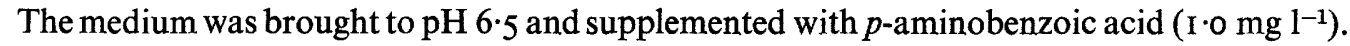
$\mathrm{MgSO}_{4} \cdot 7 \mathrm{H}_{2} \mathrm{O}$ was added separately to $0.52 \mathrm{~g} \mathrm{1}^{-1}$.

All carbon sources, except aspartic acid, were prepared as stock solutions in distilled water, brought to $\mathrm{pH} 6.5$ where necessary, and sterilized by autoclaving at $\mathrm{I} 2 \mathrm{I}{ }^{\circ} \mathrm{C}$ for $10 \mathrm{~min}$, or, in the case of sucrose and galactose, $\mathrm{x} 10{ }^{\circ} \mathrm{C}$ for $20 \mathrm{~min}$. A dilute solution of aspartic acid was adjusted to $\mathrm{pH} 6.5$ and incorporated into the final medium which was then autoclaved.

Media for plates were solidified with $\mathrm{I} \cdot 5 \%$ (w/v) Davis New Zealand agar and sterilized by autoclaving at $12 \mathrm{I}{ }^{\circ} \mathrm{C}$ for $\mathrm{I} 5 \mathrm{~min}$. The carbon source was added aseptically from stock solution to the cooled molten medium immediately before pouring the plates; these were dried before stab inoculation with conidia.

Media for liquid culture, containing the wetting agent Tween 80 diluted $1 \mathrm{O}^{-5}(\mathrm{v} / \mathrm{v})$, were autoclaved at $\mathrm{I}_{2} \mathrm{I}{ }^{\circ} \mathrm{C}$ for $\mathrm{I} 5 \mathrm{~min}$ before adding $\mathrm{MgSO}_{4}$ and carbon source from stock solutions. The medium was then distributed aseptically in $5.0 \mathrm{ml}$ samples to capped $17 \mathrm{~mm}$ diam. test tubes. The cultures were inoculated with a standard loop of conidia and held at an angle during incubation on a rotary platform shaker.

Both plates and liquid cultures were incubated at $37^{\circ} \mathrm{C}$.

Sources of agar. The various agars were obtained from commercial suppliers. Electrophoretic quality agarose was from BDH Chemicals. Agars were washed by suspension followed by filtration using 10 vols chloroform, 10 vols methanol, three washes in 20 vols ethanol and six in 50 vols distilled water.

\section{RESULTS AND DISCUSSION}

\section{Agar as carbon source for Aspergillus nidulans}

A number of workers have found that agar provides a significant carbon source for the growth of Aspergillus nidulans (Hankinson, 1974; Fiddy \& Trinci, 1975).

When conidia of $\boldsymbol{A}$. nidulans were incubated in a defined liquid medium lacking added carbon source there was essentially no growth, although a small proportion of the conidia eventually germinated to produce a single hypha. However, when dilute suspensions of conidia were plated on the same medium solidified with agar but still with no added carbon source, a large proportion of the conidia formed isolated colonies which increased in diameter at a rate similar to that on glucose plates. However the resultant colonies were typically 'sparse', poorly conidiated with a low density of mycelium. Obviously, the organism was able to derive significant quantities of carbon from the agar. There was no apparent liquefaction of the agar around the colonies.

Hankinson (1974) found that mutants defective in the utilization of glycolytic carbon sources can grow on agar plates without added carbon source, although their growth may be inhibited when the non-utilized carbon source is added. This leaky growth of hexose non-utilizing mutants on agar alone is interpreted on the basis either of a mixture of different hexoses being present in agar or of alternative metabolic routes such as the phospho-pentose 
Table I. The utilization of carbon sources by strains of Aspergillus nidulans for growth in liquid media or on agar plates

The Table shows the relative growth responses to carbon sources supplied in defined liquid media or in the same media solidified with agar. Growth yields were scored visually for the amounts of mycelium formed in comparison with the wild-type strains $\mathrm{R} 21$. The carbon sources fell roughly into two groups with respect to growth of the wild type and these were scored +++ (sucrose, alanine, aspartate and glutamate) or ++ (acetate, lactate, succinate). For each carbon source, yields were scored over a range: $+++;++;+$, poor yield; $(+)$, mycelium visible; - , no growth. Cultures were scored after incubation for I day (sucrose), 2 days (acetate, lactate, alanine, aspartate, glutamate) or 3 days (succinate). Growth on agar plates with no added carbon source was apparent after 1 day's incubation: the Table shows growth at 3 days. While the growth of the wild type on each carbon source tested on agar plates or in liquid culture was similar, this does not imply that quantitative differences in yield would not be found.

The organic acids were tested with $\mathrm{NO}_{3}^{-}$as nitrogen source; the same results were obtained when $\mathrm{NH}_{4}^{+-}$was the nitrogen source. The same results were also obtained for each of the amino acids irrespective of whether the amino acid was supplied as the sole carbon and nitrogen source, or as the carbon source with added $\mathrm{NO}_{3}^{-}$or $\mathrm{NH}_{4}^{+-}$present.

Carbon sources for growth

\begin{tabular}{|c|c|c|c|c|c|c|c|c|c|c|c|c|c|c|}
\hline \multirow[b]{2}{*}{ Strains } & \multirow{2}{*}{$\begin{array}{l}\text { Enzyme } \\
\text { lesions* }\end{array}$} & \multirow{2}{*}{$\begin{array}{c}\text { None } \\
\text { added } \\
\text { AP }\end{array}$} & \multirow{2}{*}{$\begin{array}{c}\text { Sucrose } \\
(0.02 \mathrm{M}) \\
\text { LM or AP }\end{array}$} & \multirow{2}{*}{$\begin{array}{c}\text { Acetate } \\
(0.10 \mathrm{M}) \\
\text { LM or AP }\end{array}$} & \multicolumn{2}{|c|}{$\begin{array}{l}\text { DL-Lactate } \\
(0.1 \mathrm{M})\end{array}$} & \multicolumn{2}{|c|}{$\begin{array}{l}\text { L-Alanine } \\
(0.05 \mathrm{M})\end{array}$} & \multicolumn{2}{|c|}{$\begin{array}{l}\text { Succinate } \\
(0.1 \mathrm{M})\end{array}$} & \multicolumn{2}{|c|}{$\begin{array}{l}\text { L-Aspartate } \\
(0.05 \mathrm{M})\end{array}$} & \multicolumn{2}{|c|}{$\begin{array}{l}\text { L-Glutamate } \\
(0.05 \mathrm{M})\end{array}$} \\
\hline & & & & & LM & AP & LM & AP & LM & AP & LM & AP & LM & AP \\
\hline $\begin{array}{l}\mathrm{R} 2 \mathrm{I} \\
\text { pycA3 }\end{array}$ & $\begin{array}{l}\text { Pyruvate } \\
\text { carboxylase }\end{array}$ & $\begin{array}{l}+ \\
+\end{array}$ & $+t+$ & $\begin{array}{l}++ \\
++\end{array}$ & $\begin{array}{l}++ \\
(+)\end{array}$ & $\begin{array}{l}++ \\
(+)\end{array}$ & $\begin{array}{c}++ \\
-\end{array}$ & $\begin{array}{c}++ \\
+\end{array}$ & $\begin{array}{l}++ \\
++\end{array}$ & $\begin{array}{l}++ \\
++\end{array}$ & $\begin{array}{l}+++ \\
+++\end{array}$ & $\begin{array}{c}+t+ \\
++\end{array}$ & $\begin{array}{c}+t+ \\
++\end{array}$ & $\begin{array}{c}++ \\
++\end{array}$ \\
\hline$p d h A I$ & $\begin{array}{l}\text { Pyruvate } \\
\text { dehydrogenase }\end{array}$ & + & - & ++ & $(+)$ & ++ & $(+)$ & $+t$ & $(+)$ & ++ & ++ & ++ & ++ & +++ \\
\hline acuA204 & $\begin{array}{l}\text { Acetyl-CoA } \\
\text { synthase }\end{array}$ & - & ++ & - & ++ & - & $+t+$ & - & ++ & + & ++ & $(+)$ & +++ & + \\
\hline $\begin{array}{l}\text { facB2-IOI } \\
\text { acuC203 }\end{array}$ & $\begin{array}{l}\text { Not known } \\
\text { Not known }\end{array}$ & $\begin{array}{l}(+) \\
-\end{array}$ & $\begin{array}{l}+++ \\
+++\end{array}$ & $\begin{array}{c}(+) \\
-\end{array}$ & $\begin{array}{l}++ \\
++\end{array}$ & - & $\begin{array}{l}++t \\
++t\end{array}$ & - & $\begin{array}{l}+t \\
+t\end{array}$ & $\begin{array}{l}+ \\
+\end{array}$ & $\begin{array}{c}++t \\
++\end{array}$ & $\begin{array}{l}(+) \\
(+)\end{array}$ & $\begin{array}{l}++t \\
++t\end{array}$ & $\begin{array}{l}+ \\
+\end{array}$ \\
\hline $\begin{array}{l}\text { acuD202 } \\
\text { acuE2OI }\end{array}$ & $\begin{array}{l}\text { Isocitrate lyase } \\
\text { Malate synthase }\end{array}$ & - & $\begin{array}{l}+++ \\
+++\end{array}$ & $\overline{-}$ & $\begin{array}{l}(+) \\
++\end{array}$ & $\overline{+}$ & $\begin{array}{l}+++ \\
+++\end{array}$ & - & $\begin{array}{l}++ \\
++\end{array}$ & $\overline{+}$ & $\begin{array}{l}+ \\
+\end{array}$ & $\begin{array}{l}- \\
-\end{array}$ & $\begin{array}{c}++ \\
+\end{array}$ & $\begin{array}{l}(+) \\
+\end{array}$ \\
\hline $\begin{array}{l}\text { acuK248 } \\
\text { acuM2-3oI }\end{array}$ & $\begin{array}{l}\text { Malic enzyme } \\
\text { Malic enzyme }\end{array}$ & - & $\begin{array}{l}+++ \\
+++\end{array}$ & $\overline{-}$ & $\overline{+}$ & $\overline{-}$ & $\overline{+}$ & $\overline{-}$ & $\begin{array}{l}+ \\
+\end{array}$ & $\overline{-}$ & $\begin{array}{l}++ \\
++\end{array}$ & $\overline{-}$ & $\bar{t}$ & $\begin{array}{l}- \\
-\end{array}$ \\
\hline acuF238 & $\begin{array}{l}\text { PEP } \\
\text { carboxykinase }\end{array}$ & - & +++ & - & - & - & - & - & - & - & - & - & - & - \\
\hline$a c u G 223$ & $\begin{array}{l}\text { Fructose } \\
\text { I,6-diphosphatase }\end{array}$ & $\mathrm{se}^{(+)}$ & $+t+$ & $(+)$ & + & $(+)$ & + & + & + & - & $(+)$ & $(+)$ & + & - \\
\hline acuL2I7 & Not known & - & +++ & - & + & - & + & - & ++ & - & ++ & - & $(+)$ & - \\
\hline асиHzo6 & Not known & - & +++ & - & ++ & - & ++ & - & + & - & ++ & - & ++ & + \\
\hline$a c u J 2 I I$ & Not known & - & +++ & - & - & - & - & - & - & - & $(+)$ & - & ++ & + \\
\hline acuN2-356 & Not known & - & +++ & - & + & - & - & - & - & - & +++ & - & + & - \\
\hline
\end{tabular}

LM, liquid medium; AP, agar plate.

* For details of enzyme lesions, see: pycA, Skinner \& Armitt (1972); pdhA, Romano \& Kornberg (1969); acu strains, Armitt et al. (1976). 
pathway. The implication that the carbon sources present in agar are either not hexoses or are not metabolized through glycolysis, appears to have been overlooked.

We found that glycolytic mutants lacking pyruvate dehydrogenase ( $p d h A)$ or pyruvate carboxylase ( $p y c A)$ show similar phenomena (Table I). These mutants did not grow on sucrose, glucose or galactose but grew well on other carbon sources such as acetate or glutamate. They grew on agar plates without added carbon source - though not so well as the wild-type did - but this growth was inhibited by a low concentration (I mM or less) of sucrose or glucose. Acetate non-utilizing (acu) mutants, which grew well on sucrose or glucose, did not grow at all on agar plates with no added carbon source. Taken together these observations strongly suggest that $A$. nidulans utilizes agar as a carbon source not through glycolysis but through the pathways of acetate metabolism (Kornberg, 1966).

The data presented in Table I refer to Davis New Zealand agar but other commercial agars (Difco, Oxoid, Fisons) gave essentially the same results. We first thought that the carbon source was some contaminating material, but thorough washing of the agar with chloroform, ethanol and distilled water did not greatly diminish its capacity to support growth. It is therefore unlikely that the carbon source has low molecular weight or is a fatty acid (Sykes, 1956). We also considered the possibility that the organism derived $\mathrm{C}_{2}$ compounds from residues substituted on the galactose units of the polymers, since many agarophytes contain D-galactose units bearing a pyruvic acid acetal, 4,6-O-(I-carboxyethylidene)-D-galactose, and these may constitute up to $3.0 \%$ of the polymer (Young et al., 1971). However when electrophoretic quality agarose was used in plates with no other added carbon source, growth of the wild type, and $p y c A$ and $p d h A$ strains was as good as on the commercial agars. Washing the agarose did not diminish the growth of the wild type or of the glycolytic mutants. The acu mutants did not grow on agarose plates.

It appears that $A$. nidulans utilizes agar by degradation of the polymers, although the amount of degradation is too small to cause liquefaction of the agar or to be detected as a change in the iodine staining reaction (Ng Ying Kin \& Yaphe, 1972; Hofsten \& Malmqvist, 1975). It is not clear how the agar polymers could be degraded to be utilized through the pathways of acetate metabolism (Kornberg, 1966). The occurrence of exo-glycoside $\alpha$ - and $\beta$-galactosidases in Aspergillus niger (Bahl \& Agarwal, 1972) and of an extracellular exo$\alpha$-I,3-glucanase together with other glycosidases in $A$. nidulans (Zonneveld, I $972 a, b$ ) suggests that agar might be degraded by extracellular enzymes releasing terminal galactose residues. However, if galactose residues are the principal product of agar degradation, mutant strains unable to grow with galactose as carbon source should also be unable to grow on agar alone. This is clearly not the case with the $p y c A$ and $p d h A$ mutants which are unable to utilize galactose, yet do grow on agar. Therefore it seems unlikely that galactose is the major product of agar degradation.

Ways in which agar can obscure growth tests for the utilization of potential carbon sources are illustrated in Table I. Growth of the $p d h A$ mutant, which requires a source of acetyl-CoA, on the lactate and the alanine test plates contradicts the expectation that this mutant cannot derive $\mathrm{C}_{2}$ compounds from these carbon sources. The virtual absence of growth of this mutant in liquid media containing the same carbon sources strongly suggests that agar is supplying a source of acetyl-CoA. The inability of agar to enhance the growth of the $p y c A$ mutant, which requires $\mathrm{C}_{4}$ dicarboxylic acids, on solid media containing alanine and lactate may indicate that the concentration of the compound derived from agar is not sufficient to induce the enzymes of the glyoxylate cycle (Kornberg, 1966). These findings also rationalize a puzzling feature concerning many of the revertants of $p y c A$ strains selected by their growth on sucrose agar plates (unpublished results). The majority of the revertants fail to 
grow on sucrose in liquid medium and contain suppressor mutations of the $p y c A$ lesion. It now appears likely that the suppressor mutations may relieve carbon catabolite repression of the utilization of agar as a $\mathbf{C}$ source, possibly by derepressing the formation of extracellular enzymes for agar degradation (Zonneveld, 1972 b).

In a medium containing a carbon source such as glucose but no added nitrogen source, agar supplies a significant source of nitrogen for the growth of $A$. nidulans. Thus similar difficulties to those discussed could occur when potential nitrogen sources are being tested on agar plates (Arst \& Cove, 1973; Polkinghorne \& Hynes, 1975). Under similar conditions there is barely any growth on agarose plates. The high sulphate content of agars could also complicate studies with mutants affecting sulphur metabolism.

\section{Agar inhibition of the utilization of certain carbon sources by acu mutants in A. nidulans}

Our attention was drawn to this phenomenon by the failure of an $a c u A$ mutant to grow on lactate or alanine test plates while growing well in the same medium without agar. This result was not expected from the known lesion in acetyl-CoA synthetase in the mutant. Discrepancies were also found between growth tests done in liquid media and on agar plates for other strains (Table $\mathrm{r}$ ). Mutants defective in gluconeogenic functions, particularly the non-leaky acuF mutant lacking PEP carboxykinase (Armitt et al., 1976), showed no growth on any of the carbon sources tested except sucrose. However, in several other cases, failure of acu mutants to grow on a particular carbon source in plates was not expected from knowledge of the enzyme lesions, for example the isocitrate lyase deficient $a c u D$ mutant on glutamate or succinate plates, and in each case the expected positive growth response was found in liquid media.

The reason for the lack of growth on agar media is not clear. It is conceivable that the very different physical environments may be important. Alternatively, it may be the presence of charged agaropectins in the agar which causes these effects, although this seems unlikely since we found the same inhibitory effects in test plates made up with agarose, which is neutral. The hypothesis that agar, or its cleavage products, represses the utilization or uptake of other carbon sources could explain much of the data.

We do not know if the agar effect is specific to the $a c u$ mutants. We do, however, urge some caution in the interpretation of growth tests for the utilization of organic acids, and especially amino acids, done only on agar plates, and in the conclusions drawn about the effects of mutant lesions on their metabolism.

This work was supported by the Science Research Council (grant I667-9); M.P. acknowledges a research studentship from the same source.

\section{REFERENCES}

Araki, C. (1959). Seaweed polysaccharides. Proceedings of the Fourth International Congress of Biochemistry (Vienna 1958), vol. I, pp. 15-30. Oxford: Pergamon.

Armitt, S., McCullough, W. \& Roberts, C. F. (1976). Analysis of acetate non-utilizing (acu) mutants in Aspergillus nidulans. Journal of General Microbiology 92, 263-282.

Arst, H. N. \& Cove, D. J. (1973). Nitrogen metabolite repression in Aspergillus nidulans. Molecular and General Genetics 126, I I I-I 4 I.

BAHL, O. M. P. \& AGARWAL, K. M. L. (1972). $\alpha$-Galactosidase, $\beta$-galactosidase and $\beta$ - $N$-acetylglucosamidase from Aspergillus niger. Methods in Enzymology 28, 728-734.

DUCKWORTH, M. \& YAPHE, W. (197I). The structure of agar. I. Fractionation of a complex mixture of polysaccharides. Carbohydrate Research r6, I89-197. 
FIDDY, C. \& TRINCI, A. P. J. (1975). Kinetics and morphology of glucose-limited cultures of moulds grown in a chemostat and on solid media. Archives of Microbiology 103, 191-197.

Hankinson, O. (1974). Mutants of the pentose phosphate pathway in Aspergillus nidulans. Journal of Bacteriology II7, I I 2 I-I I 30.

Hanus, F. J., Sands, J. G. \& Bennett, E. O. (1967). Antibiotic activity in the presence of agar. Applied Microbiology 15, 31-34.

Hofsten, B. V. \& MALmQvist, M. (1975). Degradation of agar by a Gram-negative bacterium. Journal of General Microbiology 87, I50-1 58.

IYER, R. \& IYER, V. (1960). Effect of agar on the inhibition of Micrococcus pyrogenes var. aureus by chlorotetracycline and other antibiotics. Antibiotic Chemotherapy ro, 409-413.

KORNBERG, H. L. (1966). Anaplerotic sequences in metabolism. In Essays in Biochemistry, vol. 2, pp. 1-31. Edited by P. N. Campbell and G. D. Greville. London: Academic.

NG YING KIN, N. M. K. \& YAPHE, W. (1972). Properties of agar: parameters affecting gel formation and the agarose-iodine reaction. Carbohydrate Research 25, 379-385.

Polkinghorne, M. \& HyNeS, M. J. (1975). Effect of L-histidine on the catabolism of nitrogenous compounds in Aspergillus nidulans. Journal of General Microbiology 87, 185-187.

REES, D. A. (1969). Structure, conformation, and mechanism in the formation of polysaccharide gels and networks. Advances in Carbohydrate Chemistry and Biochemistry 24, 267-332.

ReEs, D. A. (1972). Shapely polysaccharides. Biochemical Journal 126, 257-273.

Romano, A. H. \& KorNBerg, H. L. (1969). Regulation of sugar uptake by Aspergillus nidulans. Proceedings of the Royal Society B 173, 475-490.

Ryan, F. J. (1950). Selected methods of Neurospora genetics. Methods in Medical Research 3, 52-53.

SANDS, J. G. \& BENNETT, E. O. (1964). The effect of washed agar on the inhibitory activities of phenol. Journal of General and Applied Microbiology 10, 20I-206.

SKinNER, V.\& ARMITT, S. (1972). Mutants of Aspergillus nidulans lacking pyruvate carboxylase. FEBS Letters 20, $16-18$.

Sykes, G. (1956). (Editor). Constituents of Bacteriological Culture Media, Special Report to the Society for General Microbiology, pp. 26-30. Cambridge: CUP.

TAKEMOTO, K. K. \& LIEBHARBER, $\cdot$ H. (196I). Virus-polysaccharide interactions. I. An agar polysaccharide determining plaque morphology of EMC virus. Virology 14, 456-462.

Young, K., DUCKWORTH, M. \& YAPHE, W. (197I). The structure of agar. III. Pyruvic acid, a common feature of agars from different agarophytes. Carbohydrate Research 16, 446-448.

ZoNNEVELD, J. M. (I972a). A new type of enzyme, an exo-splitting $\alpha-1,3$ glucanase from non-induced cultures of Aspergillus nidulans. Biochimica et biophysica acta 258, 541-547.

ZoNNEveld, J. M. (1972b). Morphogenesis in Aspergillus nidulans. The significance of $\alpha$-1,3-glucan of the cell wall and $\alpha$-1,3-glucanase for cleistothecium development. Biochimica et biophysica acta 273, 174-187. 